\title{
LA AGONÍA DEL VERBO NOZIR, NUZIR 'DAÑAR' EN LAS POSTRIMERÍAS DE LA EDAD MEDIA ESPAÑOLA
}

Con tanta frecuencia y tal espontaneidad acuden los franceses y los italianos a sus respectivos verbos nuire y nuocere, productos paralelos del familiarísimo NOCERE latino, que a primera vista causa sorpresa descubrir que, en lo actual, el español carece de un equivalente exacto, ofreciendo a los locutores tan sólo dañar y hacer daño, hacer mal como instrumentos para la expresión del concepto en cuestión ${ }^{1}$. La sorpresa aumenta tan pronto como uno se entera de la previa existencia, en el español medieval y preclásico, de un verbo nozir (más tarde nuzir), que desempeñaba exactamente el papel que acabamos de postular teóricamente. A diferencia de nuire y nuocere, nozir/nuzir no medró ni en España, ni en sus antiguas colonias; su decadencia fue un proceso paulatino, cuyas etapas el material disponible nos permite observar con cierta precisión rara vez asequible en los numerosos casos de agonías y pérdidas léxicas en el nivel preliterario. Por eso mismo, podemos aspirar a sacar lecciones muy interesantes de la cuidadosa observación clínica de la enfermedad de ese verbo, ora tomándolo como unidad léxica, ora enfocando con particular atención su paradigma y la red de sus derivados ${ }^{2}$.

${ }^{1}$ Al lado del material estrictamente románico conviene colocar el abstracto nuisance 'molestia, estorbo, incomodidad, fastidio' (además, 'persona fastidiosa') que el inglés medieval pidió prestado al antiguo francés, donde todavía predominaba el primitivo sentido de 'daño'. Se explayan sobre los detalles las autoridades siguientes: C. T. Onions (ed.), The Oxford dictionary of English etymology, Oxford University Press, Oxford, 1966, p. 617a; el equipo responsable de la $3^{\mathrm{a}}$ ed., muy revisada, de Webster's third international dictionary..., Springfield, MA, 1961, p. 1548a, el cual opera con el infinitivo nuisir como el más cómodo punto de partida; y William Morris (ed.), American heritage dictionary of the English language, American Heritage, Boston, 1969-1981, p. $900 a$.

${ }^{2}$ Nos desentenderemos aquí por entero de la transmisión culta de la fa-

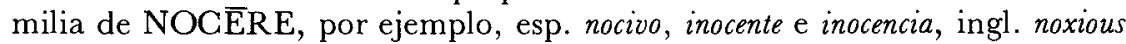


Los datos en torno a determinado problema reunidos por los comparatistas a lo largo de un siglo y medio de trabajo incesante rara vez dejan de proyectar una luz inesperada sobre alguna que otra faceta del aludido problema. Prescindiendo de las primeras etapas del comparatismo, veamos cómo el análisis de varios juicios de W. Meyer-Lübke puede prestarnos ayuda.

Ya en su primera síntesis, la célebre gramática histórica comparada ${ }^{3}$, el erudito suizo se familiarizó con varias peculiaridades de ciertos descendientes de NOCERE. Le llamó la atención la fragmentación del infinitivo (y de algunas formas afines) en francés medieval: nuisir frente a nuire (la variante que triunfó en lo moderno); la coexistencia del esquema básico con la variante incoativa en toscano: nutro frente a nutrisco en el presente del indicativo; la caprichosa presencia del verbo en algunas lenguas románicas frente a su ausencia de otras ${ }^{4}$. Dio un notable paso adelante en su libro quizás más logrado, la introducción a la lingüística romance, explicando en qué circunstancias un verbo como LUCEO, -ERE cambió de conjugación, adoptando formas como luci en rumano, luisir en francés antiguo y luzir en provenzal, español antiguo y portugués ${ }^{5}$. Claro que, me atrevo a agregar ya por cuenta mía, la transformación (bien motivada) de LUCERE en luzir pudo arrastrar también a NOCERE y DICERE, los cuales, por consecuencia, no tardaron en adoptar las formas analógicas nozir/nuzir (en lugar de nozer, ajeno al castellano) y dezir/dizir. Por último vino el diccionario etimológico del catedrático de Viena y Bonn. Merece atención un detalle: en el fondo no hay ninguna diferencia entre la primera versión (la de los años 1911-1920) y el texto definitivo de 1930-1935 en lo que concierne

e innocuous, etc., que en sí no carece de interés, pero que los hablantes ya no asociaban, que sepamos, con la corriente principal de los sucesos.

${ }^{3}$ Grammatik der romanischen Sprachen, 4 ts., Leipzig, 1890-1902, t. 1: Lautlehre $\$ \S 184$ y 441 ; t. 2: Formenlehre, $\$ \S 129,159,190,201$. Las únicas partes del paradigma total que despertaron cierto interés en el autor en aquel entonces eran el infinitivo y el indicativo igual que el subjuntivo del presente, de manera que no se pronunció sobre formas metafónicas como nuzié o nuzió.

${ }^{4}$ En algunos contextos el autor operaba, en aquella altura, con el esp. nucir (es decir, con la variante más tardía y, por lo tanto, la menos relevante); en otros, lo daba por inexistente. $\mathrm{Ni}$ al sardo, ni a los dialectos italianos concedió todavía los lugares que les correspondían.

${ }^{5} \mathrm{Me}$ refiero a la $2^{\mathrm{a}}$ ed. rev. de su Einführung in das Studium der romanischen Sprachwissenschaft, Heidelberg, 1909, \$169, con alusión al \$206. En la tercera y última edición de su obra maestra, la de 1920, abrevió el pasaje; pero Américo Castro, en su traducción del libro (1926), lo restauró entre corchetes. 
a las peripecias de NOCERE (véase el §5938). Dicho de otro modo, ya en vísperas de la primera guerra mundial Meyer-Lübke, con la ayuda de su compatriota Cario Salvioni ${ }^{6}$, se había formado una idea fija y definitiva de las zonas románicas del verbo latino, aduciendo como los respectivos infinitivos nuocere para el italiano, nógere para el sardo, nužair para el engadinés, nózi para el friulano, nuisir/nuire para el francés (a través de dos épocas), nozer para el provenzal y nucir (es decir, la variante menos característica) para el español ${ }^{7}$, separando del resto al piamontés nón$z e$ (con nasal intrusa) a causa de su significado excepcional: 'hechizar, embrujar'.

En resumidas cuentas, debemos a Meyer-Lübke dos hallazgos importantes: a) encontró un modo elegante de justificar el traslado de LUCERE (y, en su compañía, de FLORERE 'florecer') a la clase de conjugación con infinitivos en ${ }^{*}-\mathrm{IRE}^{8}$ ) con lo cual quedó explicado también, si bien sólo indirectamente, el cambio de NOCERE en *-IRE, en vista de la velar sorda que compartían, en posición idéntica, LUCERE y NOCERE; y b) creyó reconocer dos grandes lagunas en el legado del latín a los romances, faltando cualquier eco de NOCERE $\alpha$ ) al rumano y $\beta$ ) (se-

${ }^{6}$ Postille italiane al vocabolario latino-romanzo [di Gustav KÖRTING, Paderborn, 1891], trabajo incluido en las Memorie dell' Istituto Lombardo, 20 (1899), 255-278.

${ }^{7}$ Huelga insistir en la abundancia - hoy día- de guías mucho más fidedignos a los varios idiomas aprovechados para la reconstrucción de cuantos estaban a la disposición de Meyer-Lübke hacia 1910. Basta mencionar, como fuentes para la indagación futura, a MAX L. WAGNER, Dizionario etimologico sardo, t. 2, Carl Winter, Heidelberg, 1962 (el fase. 12 salió en 1960), p. 169, quien registra el verbo bajo la forma nokere (la de los dialectos centrales), subordinándole las variantes de nòyere del logudorés y nơziri del campidanés, y mencionando como miembros del paradigma nochiant y nochende (Sassari); además de los adjetivos nokkiou, etc. 'pregiudicato' e innokiou, 'scemo' como típicas de Nuori y Logudoro.

${ }^{8}$ Las dos condiciones a que atribuyó, de soslayo, el trastrueque eran: a) el carácter denominal (y no deadjetival) de FLORERE y LUCEERE, extraídos de FLOS y LUXX, respectivamente; b) la previa existencia de verbos incoativos en -ESCERE dentro del ámbito de estas dos familias. (A. ERNOUT y A. Meillet, en su magistral Dictionnaire étymologique de la langue latine, $4^{\mathrm{a}}$ ed. Klincksièck, Paris, $1959-1960$, pp. $241 b$ y $372 a-374 a$, confirmaron la sospecha de Meyer-Lübke para FLOS, declarando empero jerárquicamente iguales a LUXX y LUCEERE.) Quedando más arrimada a la función denominal la cuarta que la segunda conjugación (testigo FĪNİRE 'terminar', que se respalda en FINNIS), nada más natural que el cambio de LUCEERE en *-lRE.

${ }^{9}$ Claro que IACERE 'yacer' quedó exento de la atracción por su índole de verbo semi-auxiliar, cf. aver, poder, querer, saber, seer, tener. 
gún él) al portugués. Los detalles de la situación que se cristalizó en la península balcánica no nos conciernen hoy por hoy ${ }^{10}$. En cuanto al estado de cosas a lo largo de la costa atlántica de la península ibérica, se puede matizar el silencio de Meyer-Lübke con la observación de que en gallego sí se han conservado huellas de nocer 'dañar, perjudicar, lastimar, herir, hacer daño' y aun de nocíbele 'nocivo' (cf. el fr. nuisible), si bien el verbo principal en este terreno semántico es magoar, acompañado de mágoa 'aflicción, dolor, pena' y de otro abstracto, magoadura ${ }^{11}$. Así, parece más prudente apelar no a la total ausencia, sino a la escasez o esporadicidad de brotes de NOCERE en el Occidente de la península - escasez tanto más notable como que ${ }^{*}$ nozer también quedó excluido del importante vocabulario de verbos redactado por un anónimo lexicógrafo portugués ya en el siglo XIV ${ }^{12}$. Ahora bien, sabido es que los verbos en -er e -ir, como regla, corren parejas en español y en portugués (aunque es muy frecuente que este idioma se decida por la clase -er y aquél por -ir: ferver $\sim$ hervir, morrer morir, sofrer $\sim$ sofrir (en lo actual, sufrir), viver $\sim$ vivir, etc. $)^{13}$. Lo que, al contrario, resulta muy excepcional es que exista un testimonio en una de las lenguas mellizas y falte por completo en otra; entre las excepciones, pongo de relieve la ausencia, en español, de un equivalente congénere de preencher 'llenar' ( ${ }^{*}$ porhenchir) y la ausencia, en portugués, de una legítima contraparte de añadir (en lo antiguo, eñader). De presentarse uno de esos casos tan raros, es de rigor examinarlo en clave clínica.

${ }^{10}$ IRINa Panovf, New pocket Romanian dictionary, Bucureşti, 1982, traduce 'to harm' por a face (cuivă) rău, el que está muy a tono con to do harm to...; por otro lado, a strica corresponde a 'to damage, spoil'.

${ }^{11}$ Me dejo guiar en este asunto por Leandro Carré Alvarellos, Diccionario galego-castelán e vocabulario castelán-galego, $2^{\mathrm{a}}$ ed., Moret, La Coruña, 1933, pp. 369b, 393a, 527a. Además se emplean, como en español excepto en lo que atañe a la nasal, dano y daño, y sobrevive empecer que compartía el español medieval. Sobre mágoa < MACULA, muy común también en portugués, pueden consultarse mis Three Hispanic word studies, UCPL, 1 (1947), núm. 7, pp. 227-243, 269-282. Problema privativo del gallego es el contacto de los restos de nocer con la familia, al parecer pujante, de noxo 'asco, disgusto', noxar 'enojar, molestar', noxento 'repugnante', obsérvese el significado de noxio 'nocivo, dañoso, perjudicial'.

12 Véase la edición, muy esmerada aun en lo paleográfico, de HenRy $\mathrm{H}$. Carter, "A fourteenth-century Latin / old Portuguese verb dictionary", R'Ph, 6 (1952-1953), 71-103.

${ }^{13}$ La más útil entre mis numerosas pesquisas sobre ese asunto quizás sea la que encierra el artículo: "Excessive self-assertion in glottodiachrony. Portuguese sofrer and its Latin and Spanish counterparts", 'Lingua, 65 (1985), 29-50. 
Una importante corrección al inventario preparado por MeyerLübke que se impone de inmediato atañe a las fortunas de NOCERE en portugués medieval. Dos eruditos de primera fila, Carolina Michaélis de Vasconcelos, como autora del glosario (1922) del Cancioneiro de Ajuda, y Manuel Rodríguez Lapa, como compilador de un excelente Vocabulário galego-português (1970) que acompaña su magistral edición crítica de las Cantigas d'escarnho e de mal dizer, están de acuerdo sobre la existencia de nuzir, -er en el portugués literario del siglo XIII y documentan tal verbo, incluyendo al infinitivo, pero sin comentar su forma. El resultado normal del desarrollo debería ser *nozer; siendo muy inverosímil la infiltración de un castellanismo ya en los albores del idioma literario, queda como alternativa la hipótesis de un fuerte influjo de luzir en el producto løcal de NOCERE. Lo que sí consta es la fecha temprana de la desaparición de tal verbo portugués, de escasa o ninguna perduración en el habla dialectal.

Aclarado este detalle, volvamos a la caída en desuso de nozir en español. La conjetura que promete prestar mayor ayuda que cualquier hipótesis rival en este callejón sin salida es la suposición de que se produjo en la península un contacto duradero con otra familia léxica de gran pujanza - contacto que pudo ejercer cierto influjo negativo en las extrañas peripecias de NOCERE. No deja de ser sugestiva la sospecha de que esta incógnita fue NƯX, -CIS 'nuez', con tal que se conceda que el fitónimo latino se refería no sólo a la nuez comestible, tan apreciada en toda Europa, sino también a ciertas especies dañinas, venenosas, es decir, capaces de perjudicar la salud, de nucir a quien las devora, ya se trate de un ser humano, ya de un animal.

Para discutir esta conjetura, conviene echar una mirada a las vicisitudes de NÜCE en los romances. En la mayor parte de los brotes medievales y aun modernos del latín coloquial, la vocal tónica $u$ de esa voz se desarrolla, según era de esperar, dando lugar a [o], como se oye con toda claridad en toscano (noce) y como se adivina, sin dificultad, enfrentándose con noix (en lo actual [nwa]) en francés, que en la Edad Media todavía se escribía y pronunciaba noiz. En algunas regiones sigue predominando la vieja $[\mathrm{u}]$, heredada en línea recta del latín -así coexisten en rumano nuc 'nogal' y nucă 'nuez', mientras el sardo luce nuүe; en otras partes la $u$ da la impresión de ser secundaria (nótese nuga en parte de la zona meridional de Francia). Descontando la habitual excentricidad del dálmata (nauk), es lícito observar que sólo el portugués con la o muy abierta [ ว ] de noz; el español, con el diptongo ué 
[we] de nuez (que también atestigua la preexistencia de una [j] tónica), a la vez que el cat. nọu en estrecho enlace con ciertos dialectos occitánicos llaman la atención al estudioso de la fónética histórica ${ }^{14}$. No deja de chocar el hecho de que Meyer-Lübke, cuyo diccionario es el libro de consulta a que se acude en busca de la primera orientación imprescindible $(\$ 6009$ de la edición definitiva), al explayarse sobre la repartición geográfica de la voz en cuestión haya guardado un silencio absoluto sobre anomalías de vocalismo tan graves como aquellas de que adolescen nóz y nuez, en lugar de las soluciones "ideales"': *nôz en portugués y *noz en español ${ }^{15}$. La tesis por la que abogamos aquí es que el cambio tan chocante de NÜGE en *NŎGE podría achacarse precisamente al entronque con el verbo NOGERE 'dañar', sobrentendiéndose - por lo menos en la fase inicial - la alusión a las variantes dañosas (para los niños y el ganado) y no a las nutritivas. Pero tampoco se puede descartar desde el principio la tesis opuesta de que, sea cual fuere la última causa de la inesperada diptongación de la U en NÜCE, fue el infausto contacto posterior de esta voz con ciertas formas de nozir el que causó el decaimiento del verbo. ¿Cuál de estas dos suposiciones contrarias resulta preferible?

Cambiando de perspectiva y haciendo caso omiso de la evolución extrapenmsular del latín, dejémonos gmiar, primero, por V. García de Diego en un breve paseo por la península ${ }^{16}$. Apoyándose en las obras clásicas de Marcial Valladares Núñez (1884) y Francisco Javier Simonet (1888), sacando todo el jugo al diccionario de la Academia de Madrid, utilizando dos monografías bastante recientes de Lorenzo Rodríguez-Gastellano y un vocabulario todavía aprovechable de Vicente Ferraz y Castán (1934)

14 No puede servir de paralelo el caso de CRUX, ya que, a causa de la función simbólica del objeto, aquella voz dio lugar a un cultismo neto (cruz) en algunas provincias del Imperio; pero en francés y en italiano, eso sí, croix y croce riman con noix y noce.

15 En cuanto a la cristalización del tipo *NÜCA (que se puede inferir del occ. nuga, cat. noga, arag. nogarro 'pericarpio de la nuez', sant. des- o es-nogar 'quitar la envoltura de la nuez'), o se trata de una extensión analógica - desde luego, ya muy antigua, anterior a la asibilación de la [k] - de la - a (a imitación de la desinencia ciruel-a, manzan-a, per-a, etc.), o se extrajo esta variante con velar fija de derivados como nog-al y nog/u/-era que designan el árbol. Nuesa parece un compromiso entre nuez y noga.

16 Se trata de la segunda edición, ya póstuma (revisada por Carmen G. de D.) del Diccionario etimológico español e hispánico, Madrid, 1985, p. 839b. La primera, que no lleva fecha, salió, como me consta (por un testimonio de $\mathrm{R}$. Menéndez Pidal), en 1957. 
así como una lista de voces santanderinas compilada por José Calderón Escalada ${ }^{17}$, García de Diego ya acercándose al final de una larga carrera, regaló a sus lectores un verdadero caudal de formas dialectales, aun si se pasan por alto aquellas que, con motivo de un sufijo de derivación agregado al radical, muestran el descendiente local de NÜC- o *NOC- en posición protónica, poco reveladora ${ }^{18}$. Quizás las más dignas de atención sean aquellas formas que ostentan el diptongo [wa]: ast. nuaz, port. nuace (Río de Onor), al lado de los ast. nuoz y aun anuez (¿por falsa separación de la, una nuez?) al lado del ribagorzano nuesa. Sabido es que [wo ] y [we], igual que [wa], se remontan a la [o] tónica en un nivel preliterario ${ }^{19}$; de modo que el despliegue de una abigarrada paleta de variantes en el fondo no quita nada a la extrañeza de la transformación de NŬCE en *NÖCE, pudiendo tan sólo el mozár. nucha pretender un abolengo auténticamente clásico. (El anou alicantino muestra un notable parecido al cat. nou.)

Más sofisticado es el cuadro que trazó del intrincado desarrollo Juan Corominas, hacia mediados del siglo ${ }^{20}$. Reconoció con acierto la dificultad básica, formulándola así por anticipado ya en el primer párrafo de su extensa disquisición:

El diptongo se debe a una apertura de la vocal, que es común a los tres romances hispánicos y gran parte de la lengua de Oc, pero su causa no está bien averiguada.

17 De Rodríguez-Castelliano el autor aprovechó dos monografías sucesivas, que se ocupan de zonas distintas: La variedad dialectal del Alto Aller, Diputación-Instituto de Estudios Asturianos, Oviedo, 1952 y Contribución al vocabulario del bable occidental, Instituto de Estudios Asturianos, Oviedo, 1957. Por razones que ignoro omitió la identificación del coleccionista quien recogió la forma santanderina: fue el presbítero José Calderón Escalada. Véanse sus "Voces, en su mayor parte nombres de cosas, de uso corriente en los valles altos de la provincia de Santander...", BRAE, 33 (1953), p. 298.

${ }^{18}$ Las formas características, algunas de ellas con la $\tilde{n}$ - en lugar de la $n$ tan típica de ciertos dialectos peninsulares, abarcan las variantes siguientes: cast. nochizo 'avellano silvestre', ast. no-, ño-zal (Alto Aller), moz. nochal 'nogal', ast. nucil 'ciruela de forma de una nuez'.

${ }^{19}$ Como examen clásico del complicado desarrollo de la [ $\supset$ ] patrimonial en español antiguo y dialectal conviene citar las pp. 110-143 de la $3^{a}$ ed., muy corregida y adicionada, de R. Menéndez Pidal, Orígenes del español . . , EspasaCalpe, Madrid, 1950. En las voces mozárabes nuche y nochal la $-c h-\left[{ }^{\vee}\right]$ en lugar de la $-z$ - no encierra ninguna dificultad; pero titubeo en postular [o] u [ 0 ] para la subyacente forma del prototipo latino.

${ }^{20}$ Diccionario crítico etimológico de la lengua castellana, t. 3, Gredos, BernMadrid [1956], pp. 531a-532b. 
Las tres columnas de texto apretado que siguen rebosan de datos sueltos establecidos con todo esmero y de explicaciones sutiles, las cuales, interesantes en sí, por desgracia rara vez hacen al caso ${ }^{21}$. El escepticismo fundamental de Corominas está basado ya en el anterior agnosticismo de K. von Ettmayer y G. Rohlfs ("se comprende, pues [...] que declaren desconocida la causa"), ya en los argumentos poco convincentes presentados por una pléyade de romanistas, encabezada por G. Gróber, de la cual formaban parte W. Meyer-Lübke, F. Hanssen y J. Ronjat (este último en su conocida obra de síntesis póstuma). Estos cuatro eruditos, todos ellos de preparación muy seria, coincidieron en dar por sentada "una analogía proporcional con otros nombres de plantas con $o$ abierta, que partiera del [dendrónimo] respectivo donde la $o$ es átona y, por lo tanto, se confunde el timbre abierto con el cerrado''. Sin negar en teoría la posibilidad de tal presión, Corominas la declara insuficiente para justificar un cambio compartido por cuatro lenguas emparentadas, ya que el catalán (nọu) y el provenzal (nose, not) en compañía del gascón (nose, notz, node) confirman de lleno la idiosincrasia del español (a partir de Berceo) y del portugués. Termina con aducir el caso, a su modo de ver análogo ${ }^{22}$, de nieve frente a su prototipo NIIVE, y agrega, ya en clave un tanto menos escéptica, que el céltico KNÓVA 'nuez', que ha dejado huellas en la Italia septentrional y que, a su parecer, explica también el cat. clọva 'cáscara, esp. de nuez', quizás

${ }^{21}$ Así, merece atención lo que opina Corominas sobre nọu en catalán; sobre la grafía noxai: karydin en un glosario greco-latino conservado en un papiro; sobre varios derivados en parte poco familiares (nuecero, noceda, nocedal, nogal, nogalina, noguera, noguerado, noguerón, nogueraela, nogada, nuégado) y sobre la descendencia mozárabe, reconstruida con base en las pesquisas de Simonet y Asín Palacios: nucâres, nucila, nucúlla, etc. Con todo, la impresión que el lector saca de la lectura de este artículo y, en grado todavía más alto, del artículo siguiente, sobre la procedencia del fitónimo nueza < NODDIA (se trata de una planta trepadora medicinal), es que al ilustre filólogo barcelonés le causa mayor inquietud la dimensión catalana y provenzal del intrincado problema que la española - que sigue siendo la única relevante a nuestro estudio.

${ }^{22}$ No me parece acertado invocar un paralelismo entre las anomalías de nuez y nieve. En el caso de nuez se trata de una familia exclusivamente nominal; en cuanto a nieve, el constante compañero del sustantivo ha sido el verbo nevar, que rima con el importantísimo verbo llevar, en lo antiguo levar, cuyo núcleo vocálico en latín era una $\mathrm{E}$. Bajo la presión de lieva (en lo actual, lleva) se generalizó nieva 'cae la nieve', que a su vez amoldó el producto de NIVE, cambiándolo en nieve. Compárese el influjo paralelo que ejerció en francés neiger < NIVICATRE sobre el sustantivo neige. 
haya ejercido el influjo necesario para producir el efecto que quedaba por interpretar.

Si bien la reciente revisión del diccionario de Corominas, en colaboración con José A. Pascual, en general tendió a hacerlo todavía más monumental, el particular examen de nuez, con el agregado de alguno que otro detalle de interés subordinado, nada ganó en vigor de argumentos ni en novedad de perspectiva ${ }^{23}$. Por otra parte, un desfile de gramáticas históricas y diccionarios etimológicos continúa prestando muy escasa atención al problema de la transmisión de noz/nuez que nos comprometimos a dilucidar como esencial ingrediente de la evolución del verbo nozir/nuzir ${ }^{24}$.

Por varias consideraciones de orden filológico, llegué a la conclusión de que NOCERE, en la Antigüedad, no ejerció ningún influjo en el timbre de la vocal tónica de $\mathrm{NUX}^{25}$. Operando con el caso oblicuo (con exclusión del caso sujeto ${ }^{26}$ ) e imaginándose las vocales reinterpretadas ya según la nueva norma de la Antigüedad tardía, uno echa de ver que el léxico hispanolatino contaba con tres sustantivos cuya sílaba inicial era /no/: /nodo/ 'nudo', /nok'e/ 'nuez' y/nora/ /noro/ 'nuera' - circunstancia tanto más notable como que la $\mathrm{N}$-, en su papel de consonante inicial de palabra, a diferencia de la M- no es hoy día y nunca ha sido

${ }^{23}$ Véase el Diccionario crítico etimológico castellano e hispánico, t. 4, Madrid, c. 1985 , pp. $247 a-248 b$, en que se reitera con fidelidad absoluta lo que ya quedó sentado en 1946. El pormenor que se agrega gira en torno al fitónimo gallego (Pontevedra) nocella, que el benemérito iniciador P. Martín Sarmiento definió así: 'quitameriendas o bogallo; flor azul como jacinto'.

${ }^{24}$ La única diferencia que se divisa en medio de tanta monotonía radica en que los eruditos más alertas y escrupulosos, como Heinrich Lausberg, admiten la presencia de una dificultad todavía no subsanada (véase su Romanische Sprachwissenschaft, t. 1, $2^{\text {a }}$ ed., Berlin, 1963, §183): "unklar", en lo relativo al monoptongo de noz y al diptongo de nuez, mientras que los más atrasados pretenden ni siquiera darse cuenta de la existencia de un problema que queda por resolver; así procede, por ejemplo, ANTÉNOR NASCENTES, Dicionário etimológico da língua portuguesa, Livraria Francisco Alves, Rio de Janeiro, 1932, p. 556a.

${ }^{25}$ Por ejemplo, quien examine con detenimiento la estructura semántica y fraseológica de NUX según las fuentes literarias (Plauto, Catón, Virgilio, Ovidio, Columela, Plinio, Marcial, Frontón, etc.) no reconocerá en aquella altura cronológica y aquellos ambientes el menor enlace entre 'daño, veneno' y 'nuez', 'avellana', 'castaña', 'cono', etc.; véase P.G.W. Glare (ed.), Oxford Latin dictionary, Oxford, 1982, p. $1209 b$.

${ }^{26}$ Claro que en el Siglo de Oro de la cultura romana el puesto de NŎX estaba ocupado por el semantema 'noche'; pero tan pronto como NŎCTE se sobrepuso a NOX, ya no hubo óbice a que NÜCE se metamorfoseara en *NÖE 'nuez'. 
muy común en esta familia de lenguas ${ }^{27}$.

Ahora bien: dio la casualidad que, dentro de este tríptico, la voz /nora/, ya a partir del latín, fue atraída con cierta violencia por su opuesto léxico-semántico, a saber /s $\mathrm{kra} /$ 'suegra', en virtud de un juego que varios investigadores concuerdan en llamar “polarización léxica" 28 . La principal regla del juego exige que, en una pareja así, el compañero más fuerte - en determinado marco cultural- imponga su vocal tónica o su diptongo ascendente al compañero jerárquicamente más débil. Por deferencia a esta regla, /nora/, voz omnipresente en el mundo latino-románico, no tardó en convertirse en $/ \mathrm{n} \jmath \mathrm{ra} /$, arrastrando tras de sí a sus dos socios del tríptico. Así /nodo/, a través de la fase intermedia $/ \mathrm{n} \curvearrowright \mathrm{do} /$, se apresuró a transformarse en port. nó, ast. nuedu; mientras /nok'e/, cediendo terreno a $/ \mathrm{n}^{\mathrm{t}} \mathrm{se} /$, /n $\jmath^{\mathrm{v} e}$, terminó por convertirse en noz y nuez, con equivalentes previsibles en catalán y en la lengua de $\mathrm{Oc}^{29}$.

(Por si surge la necesidad de controlar los datos aducidos y las reflexiones a que han dado lugar con materiales entresacados de otros romances, advierto al lector que el modo más seguro de justificar la génesis del tipo *NÖPTIAE [pl.] como reemplazo del clás. NUPTIAE 'bodas' que en la remota Antigüedad acompañaba el verbo NUBO, -ERE 'casarse' [hablando de la mujer] es precisamente suponer un influjo de NÜRUS $>{ }^{*}$ NÖRA en NUPTIAE, en lo que atañe al timbre de la vocal tónica; testigos noces en francés y nozze en italiano, entre otros muchos reflejos menos familiares, esparcidos aun fuera de Francia e Italia. La trayectoria que se extiende de NÜPTIAE a *NÖPTIAE difiere en

${ }^{27}$ En un típico diccionario español-inglés, como el excelente que debemos a la pericia de Edwin B. Williams, del año 1955, las palabras que comienzan con $\mathrm{M}$ ocupan 36 páginas apretadas, mientras las de $\mathrm{N}$ y $\overline{\mathrm{N}}$ iniciales están reducidas a un escaso espacio de 8 páginas.

28 A este fenómeno apasionante, no sólo para el estudio de idiomas y de lingüística, he dedicado varios estudios ora de conjunto ora de índole monográfica, comenzando por el artículo de gran envergadura "Lexical polarization in Romance", $L g, 27$ (1951), 485-518. Entre los últimos ecos figuran mis contribuciones (sobre 'perdre' frente a 'trouver' y 'nourrir' frente a 'pourrir') a $R o, 104$ (1983), 289-315, y 105 (1984-1986), 411-461.

${ }^{29} \mathrm{La}$ mutua asociación de estas tres voces saltará a la vista para quien se fije en el §38.1.C del benemérito manual de Edwin B. Williams, From Latin to Portuguese. .., University of Pennsylvania Press, Philadelphia-Oxford, 1938 (y 1962-68). El autor menciona aparte el caso de TUSSI(M) 'tos' convertido en tosse con $o$ abierta, al revés de lo que se esperaría, por la presumible presión de la forma verbal tosse 'tose'. 
un solo respecto importante, a más de la discrepancia geográfica, de las de NODUS a *NÖDUS y de NŬX a *NÖX: debieron de coadyuvar en este caso privilegiado la afinidad de los significados igual que la semejanza de las formas ${ }^{30}$.)

Resumiendo esta larga pero indispensable digresión, parece seguro que en la Antigüedad clásica no se produjo ningún roce entre NUX y NOCERE, ya que la transformación de NUX en *NÖX, tan característica de la Península Ibérica, tiene varios paralelos, en parte extrapeninsulares. Lo más verosímil es que el foco de ese movimiento entero fue el cambio casi panrománico de NǓRUS (ya modernizado previamente en NÜRA) en *NŎRA. Ante todo, salta a la vista eran sustantivos, y no verbos, los que sucumbían, uno tras otro, pero no siempre en la misma zona ni simultáneamente, a la poderosa oleada de esta transformación $\mathrm{de} / \mathrm{nu} / \mathrm{en} / \mathrm{n} \jmath /$. Huelga insistir en que el cambio de /u:/ en / $/$ $y$, por último, en /o/ que se manifiesta en la carrera de NUTRIRE camino de nodrecer en español antiguo (cf. nodriza) nada tiene que ver con los procesos que examinamos.

Aun trazadas todas estas divisorias, pudo establecerse fácilmente, ya en la Edad Media, un contacto secundario, tardío por definición, entre a) noz, nuez y b) un sector importante del paradigma del verbo nozer, nozir. En español medieval, el pres. indic. de nozir, en particular las formas rizotónicas nuezo, nuezes, nue$z e$. . nuezen, lucían un casi chocante parecido con nuez (sg.), nuezes (pl.), aun de descontarse la pléyade de sus derivados (nozedo, etc.); y lo mismo (mutatis mutandis) había sucedido sin duda en portugués preliterario. Reforzó la semejanza, convirtiéndola en identidad, el papel - reconstruido con mucho talento por Rafael Lapesa $^{31}$ - que desempeñaba en el trancurso de dos siglos la apócope en español medieval: quien decía y escribía $a d u z, d i z, f a z$ y lu $z$ no titubearía en acudir a nuez en merma de nueze. Ora medraran de hecho algunas especies venenosas de nueces (una ojeada de aficionado a la literatura botánica nos convenció de su actual

${ }^{30}$ Remito a mi pormenorizada discusión del enlace de estos problemas bastante enmarañados en el artículo que tengo en preparación (ya muy avanzada): "The transmission into Romance of Latin NODUS, NUPTIAE, NÜRUS, and NUX: Diachronie interplay of phonetic and semantic analogy".

${ }^{31} \mathrm{Al}$ artículo muy bien conocido que publicó LAPESA en el t. 2 (1951) del Homenaje a R. Menéndez Pidal, caracterizándolo con acierto como "intento de explicación histórica", conviene ágregar ahora los comentarios que añadió al reimprimirlo en su miscelánea Estudios de historia lingüística española, Gredos, Madrid, 1985. 
existencia tan sólo en países exóticos), ora la gente muy aficionada a castañas, avellanas y nueces marchara en retirada ante el riesgo de que surgiesen dañosas supersticiones de esta clase, de todos modos es concebible que actuó el tabú. Mientras era decididamente difícil sustituir un término tan inconfundiblemente concreto como noz/nuez, por cierto no faltaban perífrasis como dañar o fazer daño para circunscribir -en caso de resultar provechosa tal circunlocución- nozer/nozir; nótese la disponibilidad latente de dommage y endommager en francés así como el provecho que sacan los anglófonos de su eco en inglés: to damage, to do damage. Así, por resultar sustituibles, los descendientes de NOGERE quedaron derrotados en esta lucha por la supervivencia, aunque en grados distintos. Nozer/nuzir no tardó en desaparecer por completo del léxico portugués, si bien consiguió sobrevivir en gallego. En español nozir, quizás más debilitado en la lengua coloquial que en la literaria, conservadora casi por definición, vegetó unos cuantos siglos más, hasta los umbrales del Siglo de Oro, convirtiéndose en nuzir (en la compañía de complir > cumplir, etc.), pero también terminó por extinguirse. Esta última fase de su breve vida, que equivalió a una lenta agonía, es la que aspira a esbozar el resto del artículo presente.

En la Edad Media, de ninguna manera eran escasos en español los verbos en -ir con la vocal o en la única o última sílaba del radical, ante todo en formas como el infinitivo y el participio pasado (pero no el presente ni tampoco el gerundio). A esta importante categoría de verbos, por cierto no todos ellos conservados en la lengua del Siglo de Oro ni menos en la moderna, pertenecían, por ejemplo:

aborrir 'aburrir' y 'aborrecer', bollir 'hervir', cobrir (igual que des-, en-cobrir), condir, conplir, contir 'acontecer', cortir, destroýr, dormir, escopir, foir 'huir', fondir 'hundir', goir 'gozar', groñir, mollir, moñir 'citar, convocar, requerir', morir, nodrir 'nutrir', ofrir 'ofrecer', oýr, or dir, podrir, polir, recodir 'contestar (con brusquedad o aspereza)' frente a sacodir, sobir, se-, so-, y aun ça(n)-bollir 'enterrar' y luego 'zambullir', sofrir, sortir (cuya existencia se deja adivinar a través de dessortir, arcaico y quizás dialectal), sorvir/sorbir, tollir 'derrengar, estropear, paralizar', tondir, tosir y trocir '(hacer) pasar'32.

${ }^{32}$ Sobre algunas de estas voces existe una extensa literatura. Cada uno de los dos tomos del Diccionario de construcción y régimen. . que salieron en vida de Rufino José Cuervo (París, 1886 y 1893; reimpresos en el Instituto Caro y Cuervo, Bogotá, 1953-1954) contiene estudios relevantes de tamaño excep- 
A este grupo bien delimitado que, en su conjunto, entraba en la capa latina patrimonial del léxico español (es lícito afirmarlo rotundamente aun cuando quedan por averiguar en definitiva ciertos pormenores de dos o tres etimologías ${ }^{33}$ ) pertenecía nozir.

cional; véanse, por ejemplo, aquellos que se ocupan de aborrecer, aburrir y bullir en el t. 1, pp. 50a-52a,80a-81a, cada uno con un excursus sobre el período anteclásico y otro sobre la etimología. Hablando de investigadores contemporáneos, observo de pasada que los valiosos trabajos de STEven N. DWOrkin sobre las formaciones participiales y seudo-participiales en -ido han producido de rechazo alguno que otro examen de un verbo en -ir que atañe a nuestra pesquisa véase su nutrida nota "The fragmentation of the Latin verb TOLLERE in Hispano- (including Luso-) Romance", $R P h, 37$ (1983), 165-173, con una extensa nota de redacción a título de apéndice (pp. 173-174). Con estar dedicado, en,el fondo, a otro problema, proyecta abundante luz sobre aborrir, aduzer/adozir, conplir, contir, descobrir, dormir, fondir, faýr, groñir, morir, nozir, aýr, podrir, recodir, sofrir, sorvir/sorbir el conocido artículo de DANA A. NELSON, "The domain of the old Spanish -er and -ir verbs...", RPh, 26 (1972), 265-305; el autor presta atención también a verbos deadjetivales: enloquir, que aquí no tomamos en consideración. Repetidas veces me he ocupado de problemas de variable enfoque afines al tema presente; he aquí algunas muestras de tal preocupación (menciono unos pocos de última cosecha): "The velar insert in the present tense, with an excursus on -zer, -zir verbs", $R P h, 27$ (1974), 304-355; "From old Spanish eñader to modern añadir, and related problems", $R P h, 28$ (1975), 512-520; "A revisionist view of the etymology of OSp., OGal.Ptg. trocir 'to pass' ", LCo, 1983, núm. 12, 92-106; “El engranaje de las peripecias románicas de FERRE y FERIRE (con particular atención a reyerta y zaherir)", MRo, 4 (1984), 161-181; "Jerzy Kurylowicz's analysis of old Spanish conjugational classes", GLing, 25 (1985), 141-170, concerniendo esta última crítica a la nota del ilustre investigador polaco: "La conjugaison en -ir de l'espagnol"', Omagiu lui Alexandru Rosetti . ., București, 1965[-671, pp. 457460. Están por salir las siguientes contribuciones: "The old Spanish verbs contir/cuntir amd cundir", Miscellanea Aurelio Roncaglia, eds. Anna Ferrari y Roberto Antonelli; e "Italian parerelapparire", Romania et Slavia Adriatica: Festschrift für Zarko Muljacić, eds. J. Kramer y G. Holtus. Huelga decir que un diccionario tan detallado como los tres (o cuatro) que debemos a la pluma de Juan Corominas también arroja luz sobre varios problemas acometidos en el presente trabajo.

${ }^{33}$ Dejo a un lado embotir (en lo actual, embutir 'llenar apretando') por tratarse de un verbo denominal, con base en boto 'odre'. Ignoro si *zorrir precedió a zurrir, que da la impresión de ser una onomatopeya. Çurzir (en lo actual, zurcir) tampoco se presta a esta clase de análisis, ya que representa un cruce de SUO, -ERE y SARCIO, -IRE. Es notablemente enrevesado el caso de esp. ant. escorrir, ya que, de acuerdo con su significado, puede enlazarse ya con CURRERE (cf. escurrir), ya con CORRIGERE, de modo que, de ser así, se trata de dos homónimos; véase mi artículo "The overlap of CURRERE, -CÚTE$\mathrm{RE}$, and COR-RIGERE in Hispano-Romance", $R P h, 38$ (1984), 127-170, con una alusión al ast. apurrir 'alargar, entregar' y espurrir 'estirar', así como 
A lo expuesto arriba sobre la vocal o propia, por definición, del radical de cada uno de tales verbos conviene agregar que alternaba obligatoriamente con la $u$ en un elevado número de formas: a saber, cuando la sílaba precedía a una desinencia cuyo rasgo característico era una yod. Esto sucedía, por ejemplo, cuando la desinencia en cuestión era el -ié del imperfecto, los -ió y -ieron del pretérito perfecto, el -iente del participio presente, el -iendo del gerundio, igual que los -iera, -ies(s)e y -iere de los tres subjuntivos subordinados, en lo morfológico, al pretérito perfecto. Además, el paradigma típico de este sector lucía dos casos muy notables de yod sumergida, la cual todavía asoma en portugués arcaico: durm-amos, -ades (en lo moderno, -áis) del pres. subj. como repercusión de DORM-IAMUS, -IATTIS ${ }^{34}$.

Tomada en cuenta esta peculiaridad del paradigma, se impone la necesidad de matizar nuestro anterior aserto, declarando ahora que se trata de un tipo de verbos en cuya conjugación alternaban, con notable regularidad, la previsible $o$ etimológica con la u producida posteriormente por la metafonía. Así no existían en absoluto, dentro del ámbito de esta variedad de conjugación, verbos con la $o$ fija, de uso independiente de cuanto seguía - como funcionaba, por ejemplo, la o nuclear de tomar. Por otro lado, sí existían verbos, en un principio quizá menos numerosos, pero a veces caracterizados por una muy alta frecuencia, con una $u$ en el radical heredada directamente de la u larga del latín - como

el trabajo en prensa, "Español correrse, corrida en dos perspectivas: la sincrónica y la diacrónica", para salir en $L E A$. El contacto de podrir y poder explica la génesis de las chocantes formas pudiente y pudiendo, si es certera la interpretación que ofrezco en $(K) R Q, 34$ (1987), 5-13. El verbo sortir, predecesor de surtir, a primera vista parece descendiente de SORTIRI, pero en realidad podria remontarse a *SURGTU, supuesto participio fuerte de SURGERE, hipótesis por la que aboga Corominas, elogiando merecidamente en ese contexto el artículo modelo de Henry y RenÉe KaHANE, "The Mediterranean term SURGERE 'to anchor' ', $R P h, 4$ (1951), 195-215. En la retorcida biografía de hundir se entrelazan ingredientes de las historias de FUNDERE, (PR $\bar{O}$ )FUNDUS 'hondo' y FUNDUS 'fondo'. Sobollir > ça(m)bullir muestra, en miniatura, un injerto de bullir en el producto de SEPELIRE.

$34 \mathrm{El}$ mutuo enlace de dormir y morir se entiende de sí mismo. Pero nótese que, en el polo opuesto del campo semántico en cuestión, los hablantes se negaron a sucumbir a la tentación de generalizar bevir, que era el descendiente típico de VIVERE en la Edad Media. Tal vez por presión de vida y muerte, coadyuvando la tradición eclesiástica de los cultismos, terminaron por prevalecer los infinitivos vivir y morir, en merma de bevir y *murir. En cuanto a oír, conservó la o como si se tratase de adelantarse al riesgo de un choque homonímico con $(h)$ uir $<$ FUGERE. 
aduzir 'traer' y luzir ${ }^{35}$; esta $u$ era casi inamovible. Desentendiéndose de unos rarísimos casos de confusión individual (como lozieron 'lucieron' y adoziendo 'trayendo', 'aduciendo'), el investigador se siente autorizado a aseverar que la fijeza de la $u$ en este último sector (enriquecido por unos cuantos cultismos como asumir, surgir, etc.), contrastando tan nítidamente con la alternancia $o / u$ de una familia bifurcada como des-, en-cobrir frente a des-, encubrió, etc., contribuyó a que, en la posterior confluencia de estos dos tipos rivales, triunfara la $u$, generalizándose en el paradigma entero: de ahí que se llegó a decir aburrir (del que no tardó en desgajarse aborrecer), cubrir (con sus dos satélites), cumplir, cundir, curtir, escupir... y nuzir. Huelga insistir en que nucir no encierra más que una tentativa de ajuste a una nueva forma de pronunciación y de ortografía, después de llevado a cabo el ensordecimiento de las sibilantes; ajuste marcadamente tardío, puesto que en el ínterin el verbo ya había empezado a caer en desuso.

Justificada así la efímera transformación de nozir en nucir a la zaga de nuzir, nos conviene dar un paso atrás y detenernos en el comportamiento de la $o$ - en la perspectiva de la flexión - antes de que esta vocal perdiera terreno ante el agresivo avance de la $u$. Según esta $o$ nuclear del verbo medieval descendía de una $O$ de la lengua madre o de una $\sigma / U$, era o no era sujeta a la prevista alternancia con el diptongo ue (o, en los albores de esta tradición, con sus variantes ua y uo). De ahí que en la fase más antigua del español se dijera y se escribiera, con perfecta obediencia a dich a norma: cuenple, pero conplir; duerme, pero dormir; muere, pero morir; tuelle, pero tollir; y, con la misma lógica, nueze, pero no$z i r$. Sin embargo, tan pronto como la $o$ del radical comenzó a mudarse en $u$ en el paradigma entero, el asunto vino a complicarse.

Para una comunidad de hablantes ingenuos que había adoptado para su idioma un programa de economía radical, resultaba un lujo excesivo mantener en su arsenal de instrumentos gramaticales un sistema de conjugación tan intrincado como el que cuidaba de la alternancia de $u$ y $u e\left({ }^{*}\right.$ murir frente a muere y al sust. muerte), al lado del tradicional de o y ue (bueno frente a bondad). Después de cierto zigzagueo, los hablantes liquidaron así la inoportuna complicación: o forzaron el verbo a abandonar su propen-

${ }^{35}$ Es de rigor distinguir el verbo patrimonial aduzir 'traer', eco directo de ADDUCERE, del neologismo docto aducir 'citar', introducido en fecha tardía. Pero no es mera coincidencia que los cultismos $a^{-}$, con-, de-, in-, re-, traducir hayan adoptado el perfecto fuerte en -duje: se observa la misma adaptación en el caso de supuse, supuesto; intervenga, intervine, etc. 
sión a diptongar, de manera que cuenple/conplir se convirtió, con el pasar del tiempo, en cumple/cumplir, al igual que tuelle/tollir se metamorfoseó en tulle/tullir, en rima con bulle/bullir, arrastrando éste tras sí el cambio de (re)bollicio en (re)bullicio. Trataron como dos casos excepcionales la pareja muy privilegiada de dormir y morir (dos verbos que se apoyaban recíprocamente), dotándola del lujo de una tríada de radicales (duerm-e, durm-ió, dorm-ir). O disfrazaron los verbos incoativos, con una $o$ protegida intrínsecamente a contir y ofrir, recurriendo a (a)contecer y ofrecer; eliminaron casi por completo, excepto como arcaísmo deliberado, a moñir; y despidieron, ya sin remedio, a nuzir en compañía de goír y trocir ${ }^{36}$.

Desde luego, no hubieran optado por una solución tan radical de no haber tenido en reserva la posibilidad de una sustitución completa, agarrándose a sinónimos tan fáciles de manejar, en lo morfológico, como dañar o hazer daño. Pero no parece arriesgado añadir a esta altura que el verbo nozir/nuzir, con anterioridad a la última crisis, había sido gravemente debilitado por sus ya aludidos roces con la familia de nuez que, ante todo, la carrera todavía más breve de su congénere portugués nozer o nuzir nos deja adivinar.

A esta conspiración de circunstancias adversas se agregó otro factor: por razones eufónicas no se desarrolló, en el caso concreto de nozir/nuzir, ningún brote en -ecer, pese al florecimiento general de verbos incoativos en español medieval. Como esta clase de verbos, al revés de lo que había sucedido a sus predecesores en latín, carecía en los idiomas románicos de cualquier matiz propio ora semántico, ora funcional, el principal denominador común de cuantos verbos gravitaban hacia esta categoría era la configuración fónica del radical. Así, a partir de cierto estadio se desarrolló

${ }^{36}$ Goir, descendiente de GAUDERE (cf. su equivalente gouvir o gouver en portugués antiguo, según el lexicógrafo $C$. de Figueiredo) y trocir, de ser acertado el étimon TR $\bar{A}(\mathrm{D}) \overline{\mathrm{U}} \mathrm{CERE}$, en el fondo ejemplifican la transmisión de verbos con el diptongo nuclear -AU-. A lo mejor, los verbos arriba citados empujaron a tosir a cambiar de clase de conjugación (de resultas cuajó toser en rima con coser), igual que al final predominó sorber y no sorvir/sorbir. Nótese que TƯSSIRE sufrió parecido (pero no idéntico) cambio en francés, donde figura ahora como tousser, quizás por chistosa asociación con cracher 'escupir'. Por añadidura, las hablantes reemplazaron a nodrir $<{ }^{*}$ NUTRĪRE (Glás. $\mathrm{NU}-$ ), después de un breve intervalo en clave incoativa (nodrecer), por el respectivo cultismo neto (nutrir). Nótese que en toser y nodrir se trata de las peripecias de una $\breve{U}$ y en sorb-er, $-i r$ de las vicisitudes de una $\breve{O}$. A veces el contraste debía de borrarse, a medida que los verbos se ponían defectivos, evitándose las formas rizotónicas. 
una fuerte afinidad mutua entre $r$ (o $r r$ ) final de radical y el tipo -ecer, como demuestra la serie siguiente: aborr-ecer, car-ecer, cr-ecer, enter-ecer, mer-ecer, nodr-ecer, par-ecer, per-ecer, podr-ecer, etc. A propósito de otras consonantes así colocadas, se puede hablar, en rigor, de mera compatibilidad: aca(d)-ecer, empe(d)-ecer; (a)cont-ecer; 'fortal-ecer; escarn-ecer, perman-ecer, $(r e)$ con-ocer, sin que los prefijos ( $a$-, des-, en-, per-, re-, etc.) hayan intervenido en el proceso. Pero las sibilantes africadas $\varsigma, x$ y $z$, así como, casi en igual grado, la $s$ y la -ss-, se oponían, por motivos transparentes, a tal elaboración: faltan en absoluto *aduz-ecer, ${ }^{*} \cos$-ecer, ${ }^{*}$ coz-ecer, ${ }^{*}$ diz-ecer, ${ }^{*}$ ex-ecer, ${ }^{*}$ faz-ecer, ${ }^{*}$ luz-ecer, ${ }^{*}$ mec-ecer, ${ }^{*}$ torc-ecer, ${ }^{*}$ tos-ecer. La falta de una escapatoria tan cómoda selló el destino de nuzir ${ }^{37}$.

A estas tres presiones de carácter interno - relativamente fáciles de identifiçar- se agregó una cuarta, externa, que contribuyó a impedir la supervivencia de nozir, y fue la feroz rivalidad de su sinónimo empecer, en un principio empe(d)ecer. Este verbo, que al comienzo de su carrera significó 'obstaculizar' (compárense su étimo, IMPĔDIRE, y su congénere francés empêcher, que fue también el punto de partida para el ingl. impeach), pasó a sugerir más bien 'perjudicar'. Aunque conviene aplazar la crónica de esa rivalidad reñida, que podría entroncar, a su vez, con las peripecias de empeçar y, en otra dimensión, con ciertos roces con los descendientes de POTIONE 'bebida' > 'veneno' (port. peçonha, esp. ponzoña), hoy por hoy se puede dar por sentado que se vislumbra en esta lucha entre nozir y empecer el raro fenómeno de que ambos contrincantes sucumbieron - casi simultáneamente.

La literatura sobre los verbos españoles de los dos esquemas casi paralelos $e$-ir y $0-i r$, con frecuente alusión a la metafonía y a la diptongación igual que a la transmisión patrimonial y a la culta, es desde luego muy abundante; el autor del presente artículo debe gran número de datos y también alguna que otra idea a sus precursores, quienes repetidas veces han llamado la atención a nozir/nuzir, en general sólo de pasada y sin hacer ninguna tentativa de encuadrar el verbo en su peculiar espacio léxico. Vistos como meros átomos en el vaivén fonético y morfológico $\mathrm{y}$, por consiguiente, relegados a un párrafo o dos de la gramática histó-

${ }^{37}$ Sólo a título de remota posibilidad cito, desde luego no como tabú for mal, sino como mera molestia, la infeliz proximidad de nozir/nuzir al núcleo nodrir/nodrecer/nutrir. Si en francés, al contrario, nourrir y pourrir más bien se apoyaban (alianza que se perfilaba ya en la Antigüedad), no hay contradicción, ya que los verbos en cuestión, en lo que atañe a la primera sílaba, no compartían más que la vocal. 
rica convencional, nozir y otros verbos de este tipo han sido objetos de la detenida atención de Federico Hanssen, con resultados muy superiores a los que había alcanzado anteriormente Adolf Zauner $^{38}$. Menéndez Pidal no pudo menos de ocuparse con este enredo de problemas a lo largo de medio siglo de indagaciones, sin colocarlo, empero, nunca en el foco de su curiosidad de filólogo, gramático o dialectólogo ${ }^{39}$. Entre los análisis de los modernistas descuella, por lo agudo y escueto, un elegante ensayo del

${ }^{38}$ Véanse ZAuner, Altspanisches Elementarbuch, Heidelberg, 1908, §131, frente a F. Hanssen, Gramática histórica de la lengua castellana, Halle, 1913, $\$ 200$ (nozir) y $\$ 387$ (nucir). Trae unos cuantos datos útiles, pero no los organiza bien, Vicente García de Diego, Elementos de gramática histórica castellana, Burgos, $1914, \S 166: 2$; así, no subraya el carácter culto de abolir; además, las formas que precedieron inmediatamente a cubro y sufro a buen seguro eran ${ }^{*} \mathrm{C} \bar{O} P R I \bar{O}$

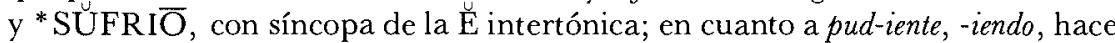
poco abogué por la hipótesis de que se trata de un traslado de formas que en lo antiguo pertenecían al paradigma de pudir 'heder' (cf., en inglés coloquial, el modismo stinking rich); véase la n. 33, supra. La discusión de las sibilantes rindió menos para el examen de nozir de lo que se podía prever. Así, J.D.M. ForD, The old Spanish sibilants, tesis de Harvard, 1897, se tomó la libertad de ni siquiera mencionar el verbo en las pp. 5-13 de su tratado; véanse los [Harvard] studies and notes in philology and literature, 7 (1900). El que noz-er pero nuz-ible figuren en el fol. $4 \mathrm{v}^{\circ}$ del Prohemio de la Gaya (mediados del s. xv) es todo lo que comunica al lector Oiva J. Tallgren (-Tuulio), Estudios sobre la "Gaya o consonantes" de Pero Guillén de Segovia ..., tesis de Helsinki, 1907, p. 83.

${ }^{39}$ Así, es mínimo el progreso que se nota en la redacción del relevante $\$ 114: 1$, b entre la $3^{\mathrm{a}}$ y la $6^{\mathrm{a}}$ (y definitiva) redacción del Manual (elementạl) de gramática histórica española, Madrid, 1914 y 1941. En ninguna de las dos versiones hay la más leve alusión a nozir / nuzir; el único agregado concierne a la diferencia entre las clases $e-i r$ y $o-i r$, que radica en que el cambio de ésta en $u$-ir no viola tanto la norma de la disimilación como la violaría el cambio de aquella en $i$-ir (si bien, agrego por cuenta mía, el vulgo no vacila en decir midir, pidir). En el cuadro de conjunto que pinta algo apresuradamente Menéndez Pidal hay varios deslices; así, cabría distinguir la vieja voz patrimonial cofffonder, cohonder, de tono religioso, del cultismo confundir, que encierra también una noción de lógica (y que terminó por sobreponerse a su predecesor): véase Diego CATALÁN, "La pronunciación [ihante] por /iffante/ en la Rioja del siglo XI", RPh, 21 (1968), 410-435, esp. 427-430. El escaso interés de ME. NÉNDEZ PIDAL por nozir / nuzir se debe, hasta cierto punto, a la ausencia del verbo del léxico cidiano; véase el Vocabulario (t. 2) que acompaña la edición monumental de Cantar (1908-1911, 1944-1946). En la sección de la Gramática (t. 1) se encuentran breves comentarios, a propósito del vocalismo verbal, sobre conplir / cunplir, escorrir / escurrir, sofrir / sufrir, contir / cuntir y morir / murir así como, a propósito de las conjugaciones y del infinitivo, sobre conplir, troçir y recudir (pp. 262, 265). No deja de ser sorprendentemente modesto el aporte de los Orígenes del español, aun en su $3^{\mathrm{a}}$ ed. muy refundida, Madrid, 1950, al problema de la "yod derivativa" (véase la p. 358). 
inolvidado estructuralista danés Knud Togeby, quien prefirió invocar en este contexto la "apofonía" 40 . Como portavoz del punto de vista de la gramática generativa, en clave ultramoderna, tiene pleno derecho a figurar James W. Harris ${ }^{41}$. Por otra parte, tampoco faltó por completo la intervención de los etimólogos, en cuyo número alguno que otro (por ejemplo, V. García de Diego) también hizo mella en la discusión gramatical ${ }^{42}$. Lamento que las circunstancias no me permitan escudriñar pormenorizadamente cada una de estas sucesivas intervenciones, cuyo propósito, por lo demás, en general no era preparar un diagnóstico de la agonía del verbo que está sobre el tapete ${ }^{43}$.

Para demostrar el gradual estancamiento del verbo esp. no-

${ }^{40}$ Se trata de unos de los últimos trabajos que salieron en vida del malogrado erudito escandinavo: “ $L$ 'apophonie des verbes espagnols et portugais en -ir", RPh, 26 (1972), 256-264.

${ }^{41}$ Aludo aquí a su artículo "Diphthongization, monophthongization, metaphony revisited", en Diachronic studies in Romance linguistics, eds. M. Saltarelli y D. Wanner, The Hague, 1975, pp. 85-97, que encierra una reacción crítica a mi propio estudio: "Diphthongization, monophthongization, metaphony: Studies in their interaction in the paradigm of the old Spanish -ir verbs", $L g$, 42 (1966), 430-472. Este último, a su vez, allanó el camino a un estudio mío de sesgo algo distinto, a causa del ahínco que pone en los cultismos: "Rising diphthongs in the paradigms of Spanish learnéd verbs", 'HR, 52 (1984), 303-333.

${ }^{42}$ Todo el que desee escuchar la voz de un etimólogo puro se dejará guiar por Juan Corominas, DCEC, Madrid-Bern [1956], t. 3, p. 527b, s.v. nucir, quien identifica con acierto el punto de partida en latín; se explaya, eso sí, sobre algunos usos medievales, a la zaga de Julio Cejador y Frauca; se detiene, con provecho para todo el mundo, en los cultismos (nocivo, inocente, inocencia, innocuo, noxa); pero al final no se atreve a averiguar la causa de la gradual decadencia de nozir / nuzir en las postrimerías de la Edad Media. El nuevo diccionario que redactó en colaboración con José A. PASCUaL ( $D C E C H$, Madrid, ca. 1985 , t. 4 , pp. $243 b-244 a$ ), agrega poco a este fondo, en parte a raíz del rastreo de C. C. Smith: cita el cultismo anticuado obnoxio y atribuye al marqués de Santillana no sólo nuciente, sino también nucible (sin preguntarse si se trata de un galicismo disfrazado). V. García de Diego, en su Diccionario etimológico español e hispánico, Madrid, [1957], p. 878a, recuerda al lector el cat. noure, pero desdibuja el cuadro, sustituyendo la esencial grafía con- $z$ - por una remozada con -c- en los infinitivos noz-er, -ir y los abstractos verbales noz-emiento, -imiento.

${ }^{43}$ Para abreviar la exposición, omito la crítica de dictámenes que se pueden leer en los conocidos manuales, desde el de Paul Förster, Spanische Sprachlehre, Berlin, 1880, p. 328, hasta el de G. B. Pellegrini, Grammatica storica spagnola, Bari, 1950, $\S 35: 7,38: 3$ y 149:3. Señalo, sin embargo, el breve y jugoso comentario de Manuel Alvar y Bernard Pottier, Morfología histórica del español, Madrid, $1983, \S \S 125$ y 127 , quienes, tras una merecida repri- 
zir/nuzir, gall.-port.nozer/nuzir, arag. nozer (y, en la última etapa del desarrollo, su agonía) se puede recurrir a varias técnicas. El procedimiento más fácil - pero, a decir verdad, algo simplistaes aprovechar el rendimiento de la estadística: el verbo se halla con mayor frecuencia en ciertos textos o autores del siglo xin (las poesías de Berceo, el Alexandre, el Apolonio) que en el Rimado de palacio o el Cancionero de Baena. En esta perspectiva, conviene descontar los textos antiguos remozados posteriormente, como el Poema de Fernán González, que desconoce nuzir ${ }^{44}$.

Pero el material que hemos conseguido recoger se presta a un análisis más interesante. Así se observa que los escritores y, presumiblemente, los hablantes daban cierto relieve a determinadas formas del paradigma (por ejemplo, el infinitivo), mientras evitaban otras (por ejemplo, el participio pasado). A bien mirar, se echa de ver que la predominancia del infinitivo se debe, ante todo, a la cristalización de algunos giros estereotipados; para ciertos hablantes el verbo en cuestión apenas si existía fuera del modismo nom' (not', no nos, etc.) puede nozir 'no puede hacerme mal':

Quando esto vidieron qe no. $\ell$ podién nocir (Berceo, Milagros, ed. B. Dutton, $156 a$, en rima con encobrir, partir, vevir); que valient una paja li podiessen nocir (var.: nucir) (Berceo, San Millán, 202d); que nocir (var. nozir) no li pudo esta az alevosa (ibid., 223d); que nocir (var. nozir) no lis puedan tues dichas enconadas (ibid., 269d); por ninguna manera non se podién nozir (Alexandre, ms.P, ed. A. Morel-Fatio, $565 d$ ); nol pueden al que lo trahe yervas enpecer (nin nozer) (ibid., 1449d); que çelada min engaño nol podrié nozir (ibid., 1454d); nunca puede al omme el mal tanto nozir (ibid., 1641c); rrobarnos ha el campo e nol podremos nozir (ibid., 2420d); nol pudieron fallar, nil pudieron nozir (Apolonio, ed. C.C. Marden, 6lc); vamos apercebidos, non nos podrán nuzir (var. E: nozir) (Rimado de palacio, ed. Kuersteiner, 149d); non podría el diablo a nós mucho nuzir (var. E: nozir)

menda a V.R.B. Oelschläger (1940) y al equipo de R. S. Boggs (1946) por ciertas omisiones, insisten en el uso de nozer en tres obras didáctico-legales redactadas en antiguo aragonés y editadas en lo moderno con todo esmero (Fueros de Aragón, Fuero de Teruel y Vidal Mayor), mencionando la discrepante preferencia del Apolonio - texto tan familiar a Alvar- por nozir. A la inversa, está lejos de ser apasionante el examen de nozir / nuzir que brinda Hildelgard Schede, Die Morphologie des Verbes im Altspanischen, Europäische Hochschulschriften, Frankfurt, 1987, núms. 24/26, p. 514.

${ }_{44}$ También falta el verbo en los glosarios bilingües de fines del siglo XIV; el de Toledo (núms. 1846, 1884) traduce NOCEO por empecer. Véase A. CAsTro, Glosarios latino-españoles de la Edad Media, Hernando, Madrid, 1936, s.v. 
(ibid., 405c); todas esas cosas que nonbras me puedan nozir sy te yo fago saber...(La estoria de Merlin, ed. K. Pietsch, fol. 295r $r^{\circ}$; ... que estos ladrones no le puedan nozir (Carlos Maynes, ed. Bonilla, cap. 31); quien Dios quier ayudar, ninguno non le puede nozir ( $D e$ un cavallero Placidas. .., fol. 30r $r^{045}$ ); nunca me podrán nozir / los que piensan enfengir (Alfonso Álvarez de Villasandino, Canc. de Baena, núm. 188, fol. 58); . . . era cosa que le podiese nuzir (otros mss.: nozir) (Pedro del Corral, hacia 1430; DCEC, s.v.nucir).

Fuera de tal contexto, el infinitivo aparece rara vez en los textos; el uso que se observa en una sola ocasión en el Alexandre: "Dixiste grant b[ $\ell$ ]asfemia, averte-ha a nozir" (P, 781b) equivale al futuro.

Para el resto del paradigma, la condición más notable es la limitación casi obligatoria del uso a la tercera persona y el predominio del singular sobre el plural. Debió de ser muy excepcional, ya en pleno siglo xiII, el empleo de otras personas (pero nótese la persona Yo en los Milagros, 325d); dicho de otro modo, antes de extinguirse por completo el verbo pasó por el estadio de la defectividad creciente, lo cual justifica, si no me engaño, nuestro uso del término "agonía”.

Con esto, empero, no terminan las restricciones. Nozir se usaba en tres tiempos, si se pasa por alto el aludido caso del futuro perifrástico. De estos tiempos, el más notable para el lingüista es el presente del indicativo, porque nos deja adivinar la pugna reñida entre nueze $(n)$ y nuze(n). Ésta es la innovadora, aquélla la heredera, en línea directa, de NÖCENT. De haber triunfado nu$z e(n)$, nozir hubiera seguido el curso de cumplir: cuenple $(n)>$ cunple $(n)$ y, a lo mejor, hubiera sobrevivido. Pero la mayoría se decidió por nueze $(n)$ — quizás por tratarse de un verbo ya en plena decadencia - y esta decisión selló, como nos consta, la adversa fortuna de nozir:

a) Nil nueze la calor, nil cuyta la friura (Apolonio, 511c); Alexandre, O, 1486d: nuezen; tanto val el amigo que no vale, como el enemigo que no nuece (Refrán [aragonés] del siglo xiv, ed. J. Ríus Serra) ${ }^{46}$.

b) Ni. $\ell$ nució más qe nuzo yo al bispo don Tello (Berceo, Milagros, 325d); mas a mí mucho me nuze esto (Leomarte, Sumas de historia troyana, ed. A. Rey, p. 143); el pecado que tú feziste, que te más

${ }^{45}$ Véase Dos obras didácticas y dos leyendas, ed. H. Knust, Madrid, 1878, SBE, t. 17.

${ }^{46}$ Véase RFE, 13 (1926), p. 369. 
agrava y que te más nuze (De una emperatriz..., ed. A. Mussafia, cap. 21$)^{47}$.

El imperfecto era nuzié (var. -ia) y el pretérito perfecto, nuzió, con metafonía (o inflexión) obligatoria mientras el hablante había optado por nozir, y no -er, como esquema básico; eran admisibles, pero nada comunes, los respectivos plurales nuzién y nuzieron (u -oron).

a) Cosa non les nuzia, bien solteras andavan (Libro de buen amor, ed. R. S. Willis, 199b);

b) Nució a Julïano la tu desavenencia (Berceo, Loores, ed. B. Dutton, 202d); ni.l nució más qe nuzo yo al bispo don Tello (Milagros, $325 d$; no li nuzió nin punto, mostróli buen talent (ibid., 365b); e temiendo de las griegas nuzióme la bárbara fechizera (Leomarte, p. 103).

Sólo a título de excepción topa el investigador con otras formas; así Dana Nelson, loe. cit., encontró en el Fuero de Alarcón el subj. pres. nuega, que debe de encerrar una mezcla de nueza o nueça con el grupo desinencial - ga de aduga, ponga, tenga, venga, andando en línea paralela a luzca, de LUCEAT, contaminado por los incoativos como conozca, -ezca, etc. Del subjuntivo del pasado estoy en condiciones de aducir un solo ejemplo, que no causará extrañeza: "Quando lo el rrey vyo pensó en ello, ca ovo pavor quel nozies[s]e" (La estoria del Rey Guillelme, fol. $\left.32 v^{\circ}\right)^{48}$.

Bien podrían existir futuros y condicionales sincopados, como *nuzré o *nuzría, ya que el grupo -zr-, tan difícil de pronunciar, alterna con $-z d r-$; precisamente este papel de consonante de transición o "tapona" (buffer consonant) desempeñaba la $d$ en lo antiguo en la comunísima variante lazdrar del verbo lazrar 'sufrir martirio' < LACERĀR $\bar{I}$. Pero los textos se niegan a ofrecer ejemplos de tales formas que la teoría nos anima a postular; dada la inconcusa realidad de yazeredes (Carlos Maynes, ed. A. Bonilla, cap. 31), lo más verosímil es que se oía de vez en cuando nozeré, * nuziría o algo por el estilo.

Otro síntoma elocuente de la decadencia del verbo es la escasez de brotes formados con la ayuda de prefijos. En atención a la métrica y por otras consideraciones, la línea $286 d \mathrm{del}$ Apolonio: "non fizo en ella el agua nuill enocimiento" exige una enmienda

47 Boletín de la Academia de Viena, 53 (1866).

48 Véase Dos obras didácticas y dos leyendas. 
en nozimiento, que con razón propuso C. Carrol Marden ya en 1922 (ed. Apolonio, t. 2, p. 141), alegando como argumento el uso de nozimiento en el Fuero Juzgo y en la traducción del Salterio por Felipe Scio de San Miguel ${ }^{49}$.

Con esto no se agotan los indicios del paulatino decaimiento de nozir/nuzir. La cristalización de un binomio reversible: empecer e nozir o, en orden opuesto, nozir e empecer, sin que, en el fondo, se agregue nada al ámbito semántico de nozir, se explica por la creciente necesidad de aclarar a los oyentes el sentido del verbo moribundo. Si empecer es el sinónimo que precede, su socio adquirirá fácilmente la forma nozer. Así, en el cap. 25 del Baladro del sabio Merlín se lee: "Dios me pueda empecer e nocer si yo te fiziere cosa que a plazer de Dios no sea"; pero en el cap. 52 se asoma el derivado nucidor que, incontestablemente, presupone el infinitivo nucir; mejor dicho, nuzir ${ }^{50}$.

Dejando a un lado el análisis histórico de nuzir, admito que no carece de interés la actitud sentimental de ciertos eruditos de lengua española quienes, en el transcurso de su labor filológica, se han dejado seducir por el encanto de un verbo irremediablemente perdido. Por haber estado lejos Rufino Lanchetas de ser el ídolo de una generación joven de investigadores, no le escatimemos nuestra simpatía al leer su veredicto: “'Lástima que un verbo como éste, tan expresivo y de tan fácil pronunciación y manejo, haya desaparecido del vocabulario de la lengua castellana! ${ }^{51}$ " Convengamos con él en llamar expresivo o elegante, y quizás de encanto insustituible el verbo aludido; pero lo de "tan fácil manejo" no corresponde exactamente a cuanto - de resultar acertado nuestro optimismo- hemos conseguido poner de manifiesto, trazando la difícil trayectoria de nozir.

YAKOV MALKIEL Universidad de California, Berkeley

${ }^{49} \mathrm{El}$ error del copista se explica fácilmente: la última palabra del verso precedente era engludimiento.

${ }^{50} \mathrm{Me}$ dejo guiar aquí por el glosario que agregó A. Bonilla y SAN MARTín al V.2 (NBAE, t. 11, Madrid, 1908) de su antología Libros de caballerías.

${ }^{51}$ Gramática y vocabulario de las obras de Gonzalo de Berceo, Madrid, 1900, p. 513. 